\title{
9. Voice-scapes: transl(oc)ating the performed voice in ethnomusicology
}

\author{
Henry Johnson
}

At the heart of ethnomusicology is the ethnographic study of people making music. As an approach to documenting, describing, analysing and understanding the symbolic sound systems in which the world's peoples live, ethnomusicological field research includes an inherent epistemological dilemma for the researcher: the question of interpretation and how best to present and represent in scholarly discourse the music, sound and people under study. Like all studies that deal with people, sound aesthetics in all cultures will necessarily lead the researcher to encounter questions relating to interpretation and translation of data collected in the field. Whether with ethnomusicology at home or in a culture other than one's own, the intersection between field research, researcher and presentation of research findings provides a challenging space of negotiation in which processes and methods of data collection and writing up of that information are highly contested. It is from this juncture that this chapter explores the notion of voice-scapes (vocal sound-scapes performed in musical ways through speech and chant) as sites that are translated using varying modes of scholarly interpretation, and as a means of sonic communication that might be translocated into discourses that rarely study its performative and musical qualities. My aim is to problematise through ethnographic description and analysis some of the challenges that face ethnomusicologists regarding the ways sounds are perceived and how they are translated and translocated into scholarly discourses.

While it is certainly the aim of any ethnographic research to present as authentically as possible the culture, subculture or individual under study, it goes without saying that the very nature of scholarly criticism is based on the reinterpretation of data and knowledge. In the field of translation studies much has been done to make visible the processes and problems of any type of translation and, within the broad area of cultural studies, the work of Homi Bhabha, for instance, has extended the notion of translation in contemporary interdisciplinary research, especially regarding his ideas on the 'translational transnational' (Bhabha 1994:173). As a discipline now entering its sixth decade, ethnomusicology has historically faced the challenge of interpreting the music and sounds of cultures that have largely been an ethnographic 'other'. While recent trends in the broadly defined discipline have done much to introduce research at 'home', as well as being more reflexive in ontological inquiry, 
questions of interpretation and translation are inevitably inescapable traits of a field based on ethnographic inquiry.

The dual nature of much ethnomusicological research concerns transl(oc)ating sound, and for this chapter that sound is produced by the voice. Music of one culture is usually translated or interpreted and then relocated in another culture, or at least another cultural context, through scholarly discourse. The space that exists between musical practice and cultural translation is one that can be highly disputed and the researcher has the responsibility to present and represent as authentically as possible the culture under study. Even a 'thick description', to use Geertz's (1973) term, is one that can embody second and third-hand ethnographic information that is sometimes far removed from its original source, where the researcher negotiates an appropriate way of interpreting the symbols of another culture. It is here that the place of interpretation can be seen to occupy a liminal space, in between two clearly defined cultural realms. There is indeed a transitional state in this interpretative pathway, the outcome being defined by individual research approach and scholarly rigour.

In this chapter, I focus on the voice and the sound-scapes it produces in contexts that are usually not considered musical settings, but nevertheless maintain musical traits. The discussion includes several examples from my own ethnomusicological research as a means of challenging the ways music researchers translate concepts, whether from one culture to another or from one individual to another in the same culture. I build on the notion of 'voicescapes' (Johnson 2004; compare Smith and Dean 2003), contexts of sound production in which the chanting voice is performed as a means of human expression, and sonic spheres that challenge definitions of 'music' and 'non-music'. ${ }^{1}$ While Smith and Dean (2003:113) use the term 'voicescapes' in a similar way to describe 'multidimensional and multidirectional projections of the voice into space, and create their own kinds of cultural geographies', in using the term, I draw more on the pioneering work of R. Murray Schafer in the field of sound-scape to describe settings in which the voice is used in musical ways yet normally considered outside the parameters of song (for example, Schafer 1977, 1992, 1993; compare Feld 1982). While Schafer does not directly make the voice a main part of his work, I extend his notion of sound-scape to one of voice-scape, in which vocal utterances create a sonic environment enmeshed in socio-cultural meaning pertaining to notions of 'sound', and subsequently challenge culturally specific definitions of the all-embracing concept 'music'. I also draw on Kuiper's (1996) work on what she terms 'smooth talkers', but extend her study to one that is related more to music research rather than linguistic/socio-linguistic analysis. Voice-scapes are part of the sound world in which we live and form meaningful sound environments through which humans communicate and express themselves through speech and chant (compare Bauman and Sherzer 1989; Ostwald 1973). They are performed sound-scapes that can have an intense 
effect on the listener as a result of the musical traits inherent in their articulation. They are socially positioned within a particular social context and create a sound world that is performed through a meaningful and sometimes chanting voice that commands a position that constructs musically a context that moves beyond everyday speech. Voice-scapes demand the attention of the listener, add expression to a social situation, position the chanter vis-a-vis the listener and are performed acts of social and paralinguistic communication. Such contexts include, for example, expressive speech and announcements at one end of a speech-chant continuum, and an auctioneer's chant, sports commentaries and demonstrations at the other end.

The socially performed voice challenges the boundaries of music and non-music and is an area that has not received the scholarly attention it deserves within music/sound/performance research. This chapter is an attempt to contribute to a discourse on the voice as a way of emphasising the musical qualities in its performed voice-scapes. I elaborate on this area of sound aesthetics in several cultural contexts, drawing on my own field research in different cultures. It is here that ethnographic study can raise questions regarding the translation or translocation of sound in the context of ethnomusicological research. By using case studies, I show some of the issues relating to the translation of ethnographic data.

\section{Speech-song continuum}

A premise underlying this discussion is that there is a continuum between the notions of speech and song. According to the Oxford English Dictionary, speech and song are defined as:

Speech: The act of speaking; the natural exercise of the vocal organs; the utterance of words or sentences; oral expression of thought or feeling.

Song: The act or art of singing; the result or effect of this, vocal music; that which is sung.

(Oxford English Dictionary 2005)

The definitions of speech and song used in this discussion are based on the use of the voice in terms of its vocal production, rather than on the way it might be perceived in any one culture. That is, one type of voice production might be considered part of music making in one culture but not in another. The idea of a speech-song continuum provides a way of locating a particular type of voice production among many, where specific techniques are used towards each end. For example, in connection with the acoustics of the voice, Sundberg (2001:123-5) notes that 'the voice organ seems to be used in the same way in singing as in speech', although 'in singing...the possibilities inherent in the normal voice organ are used in quite special ways'. In singing, the voice uses such techniques 
as breathing, vibrato, register and pitch, whereas in speech the same techniques are used but they are not as pronounced.

In this context, the chanting voice might be discussed through an ethnomusicological approach (that is, the anthropology of sound). In doing this, one soon realises that 'certain cultures make a distinction between what is referred to as speech or talking and what is referred to as song or singing. Other cultures do not necessarily make this distinction. Other cultures distinguish forms other than speech or song which to us may seem to be intermediate forms' (List 1963:3). Rather than distinguishing between speech and song as non-music and music respectively in the way that List does (see also Merriam 1964), I show that speech and song are better thought of on a continuum that does not foreground such binary opposites, and that there are musical qualities in speech and other modes of voice production along this continuum that should be explored as part of a broader anthropology of music or sound. As Seeger (1986:59) has stressed, the separation of disciplines that study different aspects of 'vocal and verbal art has had a disastrous effect on the development of our thinking about them'.

Voice-scapes are found in many cultures. While it is sometimes problematic to call something music when its performers do not conceptualise it as such, an anthropology of music must necessarily apply outsider analysis of concepts as a way of understanding or translating some of the parameters of music-making behaviour. That is, when using the paradigm for ethnomusicology suggested by Merriam (1964), for example, which takes music sound, behaviour and conceptualisation as a basic three-part model for the study of the anthropology of music, it is the conceptualisation level that is challenged when looking at sound objects and behaviour that have musical traits.

One ethnographic example that challenges the relationship between music and speech is found in Kuna indigenous discourse in the Republic of Panama:

The relationship between language structure and musical structure, like the relationship between speech and song, can raise issues familiar to ethnomusicologists...In this way linguistic and musical precision combine toward a descriptive understanding of the totality of Kuna ethnography of communication, from the perspective of a discourse-centered approach to both language and music. (Sherzer and Wicks 1982:163)

It is cultural traits such as these that help challenge the boundaries between speech and song in some cultures or by some researchers (compare Darnell 1989; Graham 1986; Klein 1986; Revel and Rey-Hulman 1993). The ethnomusicologist George List (1963), for example, makes a valuable contribution to music research when he explores the boundaries of speech and song, although more than four decades after his pivotal work in this area it seems that the subject is still one 
that is relatively understudied. What is perhaps the most striking part of List's work, however, is that while discussing speech and song as '1) vocally produced, 2) linguistically meaningful, and 3) melodic', he neglects to stress the melodically 'meaningful' aspects of the performed voice. It is these aspects of socially performed voice-scapes that are stressed in this discussion as a way of showing how the voice is musical in many ways and how people from many cultures perform the voice musically to articulate meaning through paralinguistic communication.

\section{Towards speech}

Many forms of chanting - or vocal styles very close to this - are discussed in discourses on music, particularly religious chants. When, however, voice-scapes are oriented more towards the speech end of the speech-song continuum, they seldom receive the scholarly attention in music research they deserve as performed events that have inherent musical qualities. The sonic environment produced using this mode of performed voice might not usually be conceptualised as music per se, but necessarily includes musical parameters such as pitch (see Abe 1980), vocal style, phrasing, melody and intensity. Bormann and Bormann (1972; compare Crystal 1975) have stressed the power of the voice and its ability to express non-verbal communication through vocal emphasis. While discussing the sounds of language and its vocal melodies, Bormann and Bormann note that paralinguistic communication is essential to everyday speech. There are many contexts in which the voice is performed in this way, including everyday speech, announcements and chant-like monologues.

By noting several ethnographic examples where different cultures of the world classified the voice in a variety of ways, List (1963:9) devised a classification system on the speech-song continuum that moved through speech, recitation, monotone, chant, song, intonational chant, Sprechstimme and intonational recitation. One example he noted emphasised the fact that 'the Hopi Indians of northwestern Arizona distinguish between speech, laváyi, song, táwi, and announcing [intonational chant], tíngava' (List 1963:3). List's point in mentioning this is presumably to emphasise some of the ways that different cultures classify the voice, but his classification system is devoid of any attempt to recognise the importance of the social environment in which such utterances occur. While each style might contribute to a voice-scape, it is social interaction that produces meaningful situations for the voice to be performed. It is here that performance must be emphasised as the means of giving a voice-scape its social meaning. As Enders (1990:49-50) notes, 'given the mnemonic interplay between linguistic foundations for music and musical foundations for language, it becomes unimportant to distinguish between either performative manifestation inspired by imagistic contemplation: speaking or singing, rhetoric or music'. It is when the voice is performed socially that it embodies meaning in terms of its sound 
aesthetics through vocal articulation. An example of the oral performance of the Kuna, for instance, includes parameters in the poetics and rhetoric of the voice during curing rituals that provide dramatisation (Sherzer 1986:175). The use of the voice in this context is one that helps emphasise its performative aspects in certain social situations.

Another example of vocal classification noted by List (1963:5) is of three types of 'sound communication' of the Maori of New Zealand. He points out that Maori differentiate speech (koorero), ritual chant (karakia) and song (waiata). In his discussion, List (1963:11) compares the vocal style of Sprechstimme to that used in the haka (warrior dance with chant) or, as McLean (1996:44) describes it, 'a posture dance with shouted accompaniment'. Also in connection to Maori vocal styles, waiata, according to McLean (1996:110), is a sung style that contrasts with recitation. Furthermore, karakia (prayer/lament), of which there are many kinds, might be called spells or incantations (McLean 1996:35-7) that 'are performed usually in a rapid monotone punctuated by sustained notes and descending glides at the end of phrases'.

The use of the term 'everyday speech' is particularly difficult to define. Social contexts of voice production necessarily perform the voice, but are not usually perceived to be performance events, yet they are inherently performative acts that are played out socially in just about every encounter. A voice-scape towards the speech end of the speech-song continuum might be a conversation, a speech, a sermon, an announcement or a commentary. In each, however, there is a sonic sound-scape producing meaning through vocal articulation in a musical way, not only through linguistic meaning. This might be termed the musical voice. As noted by Gerson-Kiwi (1980:29) in connection with a study of sound alienation in Asian religious rituals, 'although not generally observed, every single one of us in the course of ordinary speech runs through a broad range of melodic curves or rhetorical intonations accompanying dry speech, and dividing, for the sake of clarity, its syntactical parts'. These musical traits, especially the melodic curves and rhetorical intonations, are evident in speech phrasing, timbre and tone (compare Crystal 1975), but it is the performed part of the context that helps give it meaning during human interaction or communication. A Japanese Buddhist ritual is a typical example. There is often a 'grey' area between speech and chant or the two are mixed. There can also be vocables or guttural sounds interpolated in the speech and/or chant. In connection with Japan, for instance, one is reminded of such problems of definition when one considers the diverse behaviour that is connected with sound in culture. The Japanese do have concepts for music: the most immediate is their adoption of the English term 'music' into the Japanese word 'myûjikku'. Other terms, however, exist that are related to the sound, concepts and behaviour that encapsulate myâjikku behaviour (Johnson 1999). As Coaldrake (1989:73) has said: 
An answer to the fundamental question 'What is music?' is as essential to the appreciation of the aural phenomenon that exists in Japan as it is to the understanding of patterns of organised sound in Western culture, and just as difficult to find. The difficulties are epitomized by the fact that the authoritative New Grove Dictionary of Music and Musicians does not even have an entry for 'music'.

During ethnographic field research in Japan, while exploring a multitude of sound-scapes that challenge the notion of 'music', I became particularly aware of the way the voice was used during everyday spoken situations. Moreover, it was the ways that the spoken voice was performed in some situations that were aurally striking, especially when music traits would be seemingly exaggerated in some social contexts so as to communicate with another person. In Japan, there are many contexts in which one can hear the chanting voice, to use a more general definition of the term. For example, chanting can be found at Buddhist temples and Shinto shrines, where there is a clear melodic line. What is interesting, however, in even these contexts is that from an insider's perspective the chanting is not always perceived as music. In contrast to these chants, in everyday speech the voice is performed in a creative way in such places as a conversation between two people. For example, a young female company employee might answer the phone to a customer by using a voice that is noticeably raised in pitch in comparison with an everyday voice. Such is the extent of this raising of pitch that the speech is almost at a falsetto level. The employee might seem almost apologetic while talking to the customer, using melody and expression as a way of socially lowering herself and raising the status of the caller (a different vocabulary would be part of such a conversation). The conversation produces an aesthetic sound-scape, especially on the side of the employee, in which the voice is performed in a way in which it is altered significantly from most other social utterances.

Announcements, too, provide examples of a near-chanting voice. 'Mind the gap' or 'The next train on platform...' are typical statements at train stations that provide a voice that is intended to be noticed, is slightly exaggerated and gives a sense of authority. Television advertisements are replete with similar announcements, ones that create a voice-scape of exaggerated speech with more expression in tempo, intonation and phrasing: 'Up to 50 per cent off!', 'You won't get a better bargain anywhere else!'. On a plane one might be asked which choice of meal one wants in an everyday voice, but when the cabin crew walks down the aisle asking who wants tea or coffee the voice is usually raised in pitch and much louder and melodic than in other contexts. Even sellers adapt their spoken voice as a tool of their trade. While discussing the differences between street language and that used on the stage, Clidière (1993:138) notes that 'all sorts of entertaining speech can be found in the town: salesmen with their smooth 
talk, the voices of the preacher or the propagandist, the simple drunkard insulting passerby [sic]'. Indeed, just about any announcement, anywhere, provides a sound environment in which the voice is performed through social interaction and manipulation of its musical parameters so as to capture the attention of a listener. It is primarily the musical traits of such performative acts that allow the voice to function in this way; and it is this social situation that allows the voice to be performed musically in such settings. As a means of performed expression, the spoken voice has long been used by composers, poets and speakers alike as a musical instrument with the aim of emphasising the musical qualities of speech.

The vocal style of the American civil rights activist and preacher Martin Luther King, Jr (1929-68), is one that is replete with musical qualities. The 'I have a dream' speech delivered by King on the steps of the Lincoln Memorial in Washington, DC, on 28 August 1963 is one of many of his speeches that has a vocal style that is full of such features. His style of speech was one that was performed through a theatricality of vocal presentation using a musical voice that was almost chanting to an audience. For example:

I have a dream today.

I have a dream that one day the state of Alabama, whose governor's lips are presently dripping with the words of interposition and nullification, will be transformed into a situation where little black boys and black girls will be able to join hands with little white boys and white girls and walk together as sisters and brothers.

I have a dream today. (Clayton 1968)

This type of vocal performance is similar to a preaching style, especially that found in the evangelical church. Other spheres where the voice is performed in a similar way include politics (that is, speeches) and the armed forces (that is, orders).

\section{Towards song}

Moving along the speech-song continuum towards the song end, there are numerous contexts that display the voice using a chanting version of vocal production. This type of vocal technique is not speech and not song, but it is has more pronounced musical parameters.

While the area of announcements has already been mentioned, the topic can be extended here to show other voice-scapes that move more towards the sung style of the chanting voice. Walking through a market, one will often hear stallholders chanting what they have to sell. They seldom 'speak' the offer they have to sell, but usually 'chant' it. This chanted mode of vocal performance tends to exaggerate the words and include more pronounced musical parameters 
in the chant. Newspaper vendors too often belt their voice in a style somewhat similar to the characteristic vocal style of Martin Luther King. For example, stallholders might chant the name of the newspaper they have for sale: 'Evening Standard...Standard', 'Star...Star' or 'The Big Issue, sir'. With 'Star', for instance, the 'ar' might be stretched considerably and the final ' $r$ ' might rise in pitch and then cut off abruptly.

Another context of a similar type of chanting voice occurs in sports commentaries. A race commentator, for example, often accompanies a horserace. When the speaker begins to comment on the race, the voice is normally in a spoken style. As the race develops, however, the commentator changes the vocal style into one that is almost chant-like. The voice intensifies, it increases speed and it rises in pitch:

Racing commentaries in play-by-play mode are droned or chanted, that is, they are basically articulated in a monotone. The intonational note usually rises in semitones to a high point at the finishing post and then gradually comes down as the commentator moves through the last cycle. On the way down the commentator also moves out of this mode back into color mode with normal speech intonation. (Kuiper 1996:19)

The commentary is a performance that not only serves a function of letting the listener know race details, it creates suspense and excitement for an audience through voice manipulation.

The context of an auction too is one in which an auctioneer uses a chanting voice to sell items at the event. As List notes:

Distinctions made according to function rather than melodic type are also common in our own society. 'Auctioneering', the form of communication used by the auctioneer, is not usually considered 'song' or even 'chant'. Nevertheless, 'auctioneering' often takes the form of a monotonic chant in which the monotone and the few auxiliary tones used are quite stable. On occasion, types of melodic cadences are also used.

When speech is heightened in a socially structured situation, such as a dramatic production or in the telling of a tale, two opposite tendencies appear. The first is the negation or the levelling out of intonation into a plateau approaching a monotone. The second is the amplification or exaggeration of intonation, especially of the downward inflection that serves in most languages as a phrase, sentence, or paragraph final. (List 1963:6)

The vocal technique used by the auctioneer is known as the 'auctioneer's voice' (see Kuiper 1996). The technique is quite striking, especially with the auctioneer's 'singsong melody' (Proffitt 2005; compare Herzog 1934), and the event might 
be viewed as a performance that includes the practical function of the auctioneer keeping the sale moving while displaying verbal skills and sometimes including humour. 'Some auctioneers chant very fast - relatively speaking in a monotone manner and others use varying speeds of vocal delivery and pitches in tone...When performed by an experienced auctioneer, one often hears the chant described as a melodious song or yodel' (Ector 2005). The reasons for the use of this chant-like performance are explained as follows:

First, auctioneers have a lot to sell in a limited amount of time...Second, forcing bidders to make fast decisions is part of the strategy of auction marketing...Third, a good chant makes the auction process interesting for the bidders. The chant is the auctioneer's calling card, and the good bid callers blend art and entertainment. (Proffitt 2005)

The content of the chant contains the barest of information: 'bid prices, ask prices, and filler words' (Ector 2005). For example, an auction in the United States might go like this:

1 dollar bid, now 2,

now 2 , will ya give me 2 ?

2 dollar bid, now 3, now 3, will ya give me 3 ? 3 dollar bid, now 4, now 4 , will ya give me 4 ?

(National Auctioneers Association 2005)

In terms of the musical content of the chant, 'many people think auctioneers sound like they're singing because the chant's rhythm has a beat much like music does. The steady rhythm allows the auctioneer's chant to move more rapidly than normal speech' (National Auctioneers Association 2005). The chanting is, however, also part of the performance, especially in the way the auctioneer carries out their job. 'Besides keeping the auction moving, the fast-paced chant creates excitement and makes the auction environment entertaining' (National Auctioneers Association 2005).

There are indeed many other contexts in which similar chanting voices are used in musical ways (for example, protests, sports supporters, and so on). Many of these contexts produce voice-scapes that are chant-like and contain musical parameters such as call and response, rhythm, meter, pitch and melody. For example, when a group of protesting workers is marching along a street, their cry might be as follows: 'What do we want? More pay! When do we want it? Now!' Such a chant would be in duple time (each phrase occupying one bar) and contain call and response as a technique of communicating an idea clearly to an audience.

The use of the (non-singing) voice in musical composition is a technique that has often been used by Western art-music composers. Whether a speaking voice, 
speech-song or a chanting voice, the voice is used in ways that distinguish it from the singing voice. The American composer Steve Reich (b. 1936), for example, produced the orchestral work City Life (1994) based on the sound-scapes of New York that he heard in the late twentieth century. In this work, Reich makes use of the voice of a street seller and builds around the chant in terms of sampling and transforming its sound. In Waffender's (1995) film of the making of this work, a street seller is clearly seen chanting 'Check it out...Every item $\$ 10$, check it out...Excuse me young lady, check it out'. The last phrase is extremely exaggerated with an extended ' $u$ ' in 'excuse' and ' $e$ ' in 'check'. Reich builds on this chanting in a section of his work around the melody of the chanted phrase 'Check it out'.

Some of Reich's earlier works also use the spoken voice as a building block for his compositions. It's Gonna Rain (1966) uses a preacher's voice and Come Out (1966) uses the single phrase 'Come out to show them'. In Come Out, the voice of a survivor of a race riot is used and manipulated through different channels. Also, The Cave (1993) is one of Reich's operas that uses spoken words of interviews with Israeli, Palestinian and American people on the history of The Cave at Hebron. An interview by Andrew Ford with Reich helps show the composer's ideas while using the spoken voice as a structuring tool in his compositions:

Andrew Ford: I suppose it was really 'Different Trains' was it, where you returned to the spoken voice?

Steve Reich: Yes, well basically what happened was that after doing 'It's Gonna Rain' and then 'Come Out' in 1966, I felt I didn't want to sit around here making tapes, I'm a composer, I want to write live music, and I made that transference from the tape medium to the live music, and basically didn't look back. The only electronics I used between 1967 and 1988 were microphones to amplify the ensemble. In 1988 I was asked by Betty Freeman to write a piece...for the Kronos Quartet, and I became aware in pop music of the sampling keyboard. The sampling device is basically a computer that records sound as a keyboard interface, so that you can play what you record by playing keys on the keyboard. This was like an IBO kind of technology, which I had thought, was just made for me personally. It didn't pretend to imitate a live instrument the way synthesisers will imitate a trombone or a violin. Basically you bring it home from the store, you plug it into the wall, you press middle-C and nothing happens. You have to record something into it and the possibility of bringing in things from the outside world into music of this time, not with tape but something that could be played just by playing on the third beat of the fourth measure, was exceedingly attractive. I felt that I wanted to go back to these tape pieces, but now instead of as if they 
were music, they could literally become part of the music. So in 'Different Trains', which was a sort of line in the same kind of piece, every time you hear a woman's voice [it's] doubled by the viola, and every time you hear a man's voice, it's doubled by the cello, and the vocal melodies, the speech melodies are the melodic cells that generate the entire piece. So it was finally a kind of fusion of bringing back the old ideas from the '60s along with tape pieces, and saying, OK, now they will serve as integral parts of a piece of live music. (Ford 2003)

In another interview, Reich further illustrates some of these points:

Weidenbaum: I was co-editing a magazine called Classical Pulse! at the time and K. Robert Schwarz did a story for us about that. But I have spoken with Scott Johnson about his I.F. Stone stuff, which really affected the way I heard voices. Did your work similarly affect you the way you yourself heard people speak?

Reich: Sometimes yes, but basically there are languages in the world, that we don't speak, you and I, but in Africa for instance, where - they're called tonal languages - if you don't have the melody right, then you don't have the meaning right. But even in English, American English, if someone [says] 'no', 'No!', or, 'erm, no', those are three different statements. We are used to living with what I would call 'speech melody' hovering over everything we say-it's happening right now, and it's the emotional water [starts to laugh] in which our words swim. (Weidenbaum 2004)

The last example illustrated here regarding the blurred boundaries between speech and song is found in Tibetan Buddhist spelling chant. Rose (2001), for example, discusses this type of chant in terms of its musical qualities, especially that relating to structure (for example, rhythm, metre and pitch):

The musical structure provides for a small choice of rhythmic-melodic units at each beat. These units make use of three basic pitch levels - high, mid, and low - with an additional super high pitch that is only found in high falls and very rarely in eighth-note pairs. The choice of rhythmic-melodic unit is restricted to a large extent by the syntactic and phonological properties of the spelling sentence, especially the tonal structure of syllables and position within a phrase. (Rose 2001:203)

In many cultures, prayer involves chanting, a behaviour that has inherent musical traits, although its practitioners do not always conceptualise their behaviour as musical. 


\section{Closing thoughts}

Humans structure sounds in many ways. The study of music sound per se will not help in the understanding of the sociological processes involved in its performance, nor will it further the understanding of music as culture. While Merriam's (1964) paradigm for ethnomusicology includes the analysis on three interrelated levels of music, concepts and behaviour, there is inherent in this model the problem of establishing exactly what music is or is not. Forgetting the problems with terminology and the cultural bias that one has concerning the boundaries in one's own culture of concepts such as 'music' and 'sound', I am arguing here that there are universal forms of human behaviour where sound can be placed within an area of culture for analysis as humanly organised sound - the idea of voice-scapes helps illustrate this point.

The notion of transl(oc)ating sound is at the heart of ethnomusicological method. Reflecting on the ways music travels, whether within its own culture or interpreted and presented through scholarly discourse to other cultures, the thoughts presented in this study have been intended to problematise some of the practices that are central to ethnomusicological study: the translation and relocation of sound (in this case, sound produced by the voice). Interpretation and scholarly rigour are of course important factors in this process, ones that seek best to present and represent the music and people under study. This chapter has shown some of the grey areas of acoustic sound-scapes that are not always considered music, yet have inherent musical and performative traits that allow them to be considered in discourses on music. The discussion has shown, therefore, that there are many sound-scapes and voice-scapes alike that are still to be explored within music research. An understanding of these 'scapes' will help ultimately in the understanding of the ways people make music within and between many sound environments.

\section{References}

Abe, Isamu 1980, 'How vocal pitch works', in Linda R. Waugh and C. H. van Schooneveld (eds), The Melody of Language, University Park Press, Baltimore, pp. 1-24.

Bauman, Richard and Sherzer, Joel (eds) 1989, Explorations in the Ethnography of Speaking, Second edition, Cambridge University Press, Cambridge.

Bhabha, Homi K. 1994, The Location of Culture, Routledge, London.

Bormann, Ernest G. and Bormann, Nancy C. 1972, Speech Communication: An interpersonal approach, Harper \& Row, New York.

Clayton, Ed 1968, Martin Luther King: The peaceful warrior, Illustrated by David Hodges, Third edition, Prentice-Hall, Englewood Cliffs, NJ. 
Clidière, Sylvie 1993, 'Voix de traverse: Parole et spectacles de rue', in Nicole Revel and Diana Rey-Hulman (eds), Pour une Anthropologie des Voix, L'Harmattan, Paris, pp. 197-207.

Coaldrake, Kimi 1989, 'Breaking the sound barrier: the inner world of Japaense musi', Miscellanea Musicologica, vol. 16, pp. 71-8.

Crystal, David 1975, The English Tone of Voice, Edward Arnold, London.

Darnell, Regna 1989, 'Correlates of Cree narrative performance', in Richard Bauman and Joel Sherzer (eds), Explorations in the Ethnography of Speaking, Second edition, Cambridge University Press, Cambridge, pp. 315-36.

Ector, Cedric J. 2005, Understanding the Auctioneer's Chant, viewed 26 November 2005, <http://www.elac-llc.com/html/auction-chant.html>

Enders, Jody 1990, 'Visions with voices: the rhetoric of memory and music in liturgical drama', Comparative Drama, vol. 24, no. 1, pp. 34-54.

Feld, Steven 1982, Sound and Sentiment: Birds, weeping, poetics, and song in Kaluli expression, University of Pennsylvania Press, Philadelphia.

Ford, Andrew 2003, 'Interview with Steve Reich', Radio National, 8 February 2003, viewed 26 November 2003, <http://www.abc.net.au/rn/music/mshow/s780640.htm>

Geertz, Clifford 1973, The Interpretation of Cultures, Hutchinson of London, London.

Gerson-Kiwi, Edith 1980, 'Melodic patterns in Asiatic rituals: the quest for sound alienation', Israel Studies in Musicology, vol. 2, pp. 27-31.

Graham, Laura 1986, 'Three modes of Shavante vocal expression: wailing, collective singing, and political oratory', in Joel Sherzer and Greg Urban (eds), Native South American Discourse, Mouton de Gruyter, Berlin, pp. 83-118.

Herzog, G. 1934, 'Speech melody and primitive music', Musical Quarterly, vol. 20, pp. $452-66$.

Johnson, Henry 1999, 'The sounds of Myûjikku: an exploration of concepts and classifications in Japanese sound aesthetics', Journal of Musicological Research, vol. 18, no. 4, pp. 291-306.

Johnson, Henry 2004, 'Voicescapes: the (en)chanting voice and its performance soundscapes', Soundscape: The Journal of Acoustic Ecology, vol. 5, no. 2, pp. 79-98.

Klein, Harriet E. Manelis 1986, 'Styles of Toba discourse', in Joel Sherzer and Greg Urban (eds), Native South American Discourse, Mouton de Gruyter, Berlin, pp. 213-35. 
Kuiper, Koenraad 1996, Smooth Talkers: The linguistic performance of auctioneers and sportscasters, L. Erlbaum Associates, Mahwah, NJ.

List, George 1963, 'The boundaries of speech and song', Ethnomusicology, vol. 7, pp. 1-16.

McLean, Mervyn 1996, Maori Music, Auckland University Press, Auckland.

Merriam, Alan P. 1964, The Anthropology of Music, Northwestern University Press, Evanston, Ill.

National Auctioneers Association 2005, All About the Auctioneer's Chant, viewed 26 November 2005, <http://www.msaa.org/chant.php>

Ostwald, Peter F. 1973, The Semiotics of Human Sound, Mouton, The Hague.

Oxford English Dictionary 2005, Oxford English Dictionary, [Online edition], viewed 26 November 2005, <http://dictionary.oed.com/>

Proffitt, Steve 2005, 'The chant-real or illusion?', viewed 26 November 2005, <http://www.maineantiquedigest.com/articles/ethi0300.htm>

Revel, Nicole and Rey-Hulman, Diana (eds) 1993, Pour une Anthropologie des Voix, L'Harmattan, Paris.

Rose, Philip J. 2001, 'Sbyor Klog — a musical and linguistic description of Tibetan spelling chant', in Hannes Kniffka (ed.), Indigenous Grammar Across Cultures, Peter Lang, New York, pp. 161-216.

Schafer, R. Murray 1977, The Tuning of the World, McClelland and Stewart, Toronto.

Schafer, R. Murray 1992, 'Music, non-music and the soundscape', in John Paynter, Tim Howell, Richard Orton and Peter Seymour (eds), Companion to Contemporary Musical Thought. Volume 1, Routledge, London, pp. 34-45.

Schafer, R. Murray 1993, Voices of Tyranny: Temples of silence, Arcana, Ontario.

Seeger, Anthony 1986, 'Oratory is spoken, myth is told, and song is sung, but they are all music to my ears', in Joel Sherzer and Greg Urban (eds),

Native South American Discourse, Mouton de Gruyter, Berlin, pp. 59-82.

Sherzer, Joel 1986, 'The report of a Kuna curing specialist: the poetics and rhetoric of an oral performance', in Joel Sherzer and Greg Urban (eds), Native South American Discourse, Mouton de Gruyter, Berlin, pp. 169-212.

Sherzer, Joel and Wicks, Sammie Ann 1982, 'The intersection of music and language in Kuna discourse', Latin American Music Review, vol. 3, no. 2, pp. $147-64$. 
Smith, Hazel and Dean, Roger T. 2003, 'Voicescapes and sonic structures in the creation of sound technodrama', Performance Research, vol. 8, no. 1, pp. 112-23.

Sundberg, Johan 2001, 'The voice', in Stanley Sadie (ed.) and John Tyrrell (ex. ed.), The New Grove Dictionary of Music and Musicians. Volume 1, Second edition, Grove, London, pp. 120-5.

Waffender, Manfred (writer and director) 1995, City Life, ZDF.

Weidenbaum, Marc 2004, 'Interview with Steve Reich', viewed 26 November 2005, <http://www.disquiet.com/stevereich-script.html>

\section{Endnotes}

${ }^{1}$ In this discussion, I use the term 'chant' according to the Oxford English Dictionary (Online edition): 'A singing intonation or modulation of the voice in speech; a distinctive intonation.' 